\title{
CARLOS AUGUSTO DE FIGUEIREDO MONTEIRO: O DOCENTE E O GEÓGRAFO DO DEPARTAMENTO DE GEOGRAFIA DA USP
}

\author{
Adilson Avansi de Abreu*
}

\section{RESUMO:}

Este artigo contém uma exposição a respeito do papel desempenhado pelo professor Carlos Augusto de Figueiredo Monteiro entre 1968-1987 no Departamento de Geografia da Universidade de São Paulo.

\section{PALAVRAS-CHAVE:}

Carlos Augusto de Figueiredo Monteiro, atividades científicas e acadêmicas, Departamento de Geografia.

\section{ABSTRACT:}

This paper contains some explanation about the role assumed by professor Carlos Augusto de Figueiredo Monteiro between 1968-1987 at the Department of Geography of the University of São Paulo.

\section{KEY WORDS:}

Carlos Augusto de Figueiredo Monteiro, scientific and academic activities, Department of Geography.

Aprendi com o Prof. Carlos Augusto um provérbio piauiense, que me vem à memória, ao atender, com satisfação, o pedido que me foi feito para escrever estas notas. Diz o ditado que "vaqueiro só fala de boi, velho do que já foi."

Vou falar, portanto, do que já foi, pois vou me limitar ao período em que ele foi professor do quadro ativo do Departamento, entre os anos de 1968, quando foi contratado, e 1987, quando se aposentou. Será um relato apenas de memória e centrado em sua atuação acadêmica. Poderia escrever também sobre o amigo, mas isto fica para outra oportunidade. Abrange um período de cerca de duas décadas, que influenciaram fortemente os alunos que tiveram o privilégio de freqüentar o curso de Geografia neste anos, que foram marcados politicamente pela ação de um governo autoritário, originado pelo golpe de 1964 e que se fechou ainda mais a partir do ato institucional no 5, de 1968.

No contexto da crítica ao governo militar desenvolveu-se, naquele período, entre parte dos geógrafos brasileiros posicionamento e ação que conduziram a uma forte reação ideológica, canalizada para reformular a Associação dos Geógrafos Brasileiros, de um lado e que originou um movimento de crítica e ruptura com os cânones científicos que haviam institucionalizado o conhecimento geográfico 
na Universidade Brasileira. São as décadas da chamada revolução teorética quantitativa, em uma vertente, e do desenvolvimento da geografia crítica, em outra vertente, que sucedeu outras propostas renovadoras, como o da geografia ativa.

Neste ambiente emergiu uma postura ideológica de base política-econômica-social como paradigma para a Geografia, no contexto da qual os geógrafos que trabalhavam os temas da Geografia Física passaram a ser tratados por grupos mais radicais como verdadeiros "estranhos no ninho", quando não simplesmente desqualificados como neopositivistas conservadores.

Visto deste início do século XXI, este pano de fundo para o ambiente entre os geógrafos daquela época, aparece com tonalidades esmaecidas. Nos anos 70 e 80, todavia, havia um conflito intelectual, que em certas situações chegava a ser dramático, pela interferência de posturas radicais politicamente motivadas. A alteração deste panorama começa a se fazer principalmente a partir de 1989, com a queda do Muro de Berlim, a reunificação da Alemanha e a dissolução da União Soviética, além do processo de redemocratização do país. Foi porém em um ambiente ideologicamente tenso no Departamento de Geografia que o Prof. Carlos Augusto atuou e serviu de referência cultural e científica para um grande número de alunos.

Quando o Prof. Carlos Augusto chegou ao Departamento, eu era estudante e residia no Conjunto Residencial da Universidade de São Paulo, o CRUSP. Era também auxiliar de documentação do extinto Instituto de Geografia e instrutor voluntário do DG. Vivia o e no Departamento de Geografia. Desta forma, já conhecia o valor acadêmico e científico do Prof. Carlos Augusto, através de relatos e referências bibliográficas que recebi de Dona Elina de
Oliveira Santos e do Prof. Aziz Nacib Ab'Saber. Aguardava sua chegada com expectativa e quando isto ocorreu procurei me aproximar dele, de início com a timidez do aluno e depois com a sinceridade do amigo. É uma grande amizade até hoje e um aprendizado permanente.

Recentemente, quando recebeu o título de "Professor Emérito" da FFLCH da USP, o Professor Carlos Augusto de Figueiredo Monteiro denominou sua exposição com o seguinte título "Para viver a Universidade: a liberdade entre a ousadia e a humildade". Sem dúvida alguma foi uma escolha adequada para seu perfil e como caracterização concisa de sua atuação no Departamento de Geografia.

Liberdade, entre a ousadia e a humildade, esta é a postura que ele praticou, que motivou e que sustentou seu pensamento e sua atuação.

A liberdade permitia uma postura crítica em relação aos textos e autores que ele introduzia em seus cursos de graduação e de pós-graduação. Ela motivava um diálogo permanente e formador do caráter acadêmico dos alunos no campo da geografia, estimulando muito mais dúvidas e indagações do que verdades e certezas estabelecidas, o que produzia um contraste com as posições ideologicamente radicais.

No exercício da atividade docente, preparava suas aulas de forma perfeccionista e a cada novo ano as reformulava em função de uma auto-crítica severa. Os cursos foram seminais para todos que deles puderam desfrutar.

Mesmo ministrando conteúdos
específicos, como climatologia,
geomorfologia, fisiologia da paisagem ou
planejamento, para citar alguns, a
abordagem era sempre feita com a
perspectiva do todo geográfico e em
consonância com o referencial teórico e
crítico. Assim, ao discutir o papel da


Carlos Augusto de Figueiredo Monteiro: o docente e o

geógrafo do Departamento de Geografia da USP, pp. $07-10$

geomorfologia como estruturadora de algumas etapas do conhecimento geográfico, explorava suas bases teóricas, filosóficas e epistemológicas permitindo aos alunos identificar na teoria do ciclo geográfico de Davis, uma proposta claramente antipositivista, na corrente crítica desencadeada por Bergson, valorizando a intuição e a dedução.

Ao abordar os temas da geomorfologia climática e processual, evidenciava as interações entre as estruturas geológicas, os climas, a vegetação, os processos, os depósitos e a intervenção humana, demonstrando, sob o ponto de vista de didática refinada, as relações entre o homem cultural e economizante, e as abordagens de Edwin Fels, sobre a geomorfologia antropogenética, e a de Erhart sobre a resistasia.

Estas análises e proposições tinham propostas próprias e originais, que ele havia começado a desenvolver em trabalho metodologicamente inovador, que antecedeu no Brasil em muito a introdução do estudo dos geossitemas. Esta abordagem integradora e de síntese foi por ele proposta ao chefiar, na Assembléia da AGB de Penedo, em 1962, a equipe de pesquisa de campo do Baixo São Francisco, cujo resultado foi publicado pela AGB com o título de "Aspectos Geográficos do Baixo São Francisco".

A introdução entre seus alunos da metodologia sistêmica no campo da Geografia, foi feita de forma segura, evitando-se a aplicação acrítica de modelos propostos e testados em outras realidades.

Julgo desnecessário lembrar seu papel no campo da renovação dos estudos de climatologia. Prefiro acentuar seu perfil de geógrafo e de professor de geografia, que sabia integrar, com maestria, a análise do natural e do social na construção do paradigma geográfico e sua aplicação nos estudos de planejamento. Foi, alías, este perfil que atraiu para seus cursos e seminários ministrados com base no Laboratório de Climatologia do Instituto de Geografia muitos especialistas com outra formação acadêmica, entre os quais merecem destaque os arquitetos, como Rosa Klias e Jorge Wilheim, por exemplo.

Além da sala de aula o outro espaço por excelência do Professor Carlos Augusto foi exatamente este Laboratório de Climatologia. Nele interagia com os alunos de graduação e de pós-graduação assumindo o papel de mestre, no sentido mais nobre do termo, mas também como amigo.

$\mathrm{Na}$ pós-graduação seu papel foi fundamental. Orientou parte dos últimos alunos inscritos pelo antigo regime da USP (além de mim, também os Professores Augusto Umberto Vairo Titarelli, José Bueno Conti e a Professora Lucy Pinto Gallego, do Rio de Janeiro) e integrou a Comissão de Pós-Graduação da Faculdade, que implantou o sistema em vigor, sob a presidência do Prof. Antonio Cândido de Mello e Souza. Foi o autor do primeiro relatório fornecendo um balanço da Pós-Graduação do Departamento de Geografia, tendo ainda orientado inúmeros alunos de mestrado e doutorado no atual sistema.

O Professor Carlos Augusto viajava com freqüencia para o exterior, por motivação própria ou a convite. Após seu retorno, os alunos colhiam enormes benefícios com as referências bibliográficas atualizadas que ele trazia e compartilhava, bem como suas exposições acompanhadas de críticas e complementações sobre o desenvolvimento da geografia, da ciência e da cultura nos grandes centros de pesquisa da Europa e dos Estados Unidos. Foi deste modo consolidando uma contribuição teórica, metodológica e técnica no campo da geografia e sua aplicação. 
Nesta fase o reconhecimento de sua contribuição à ciência se evidenciou e, como decorrência, foi muito solicitado para trabalhos de assessoria e planejamento, executados por órgãos públicos e privados em todo o Brasil. Especial destaque merece sua atuação na Bahia.

Ele ofereceu uma contribuição fundamental aos trabalhos de extensão, norteando claramente o papel que os geógrafos da Universidade deveriam exercer, colaborando na solução de problemas urbanos e ambientais. Neste processo ele refinou, metodológica e tecnicamente, a abordagem dos problemas ambientais e publicou diversos trabalhos de grande repercussão.

Nos últimos anos de sua presença no quadro de docentes ativos da Universidade, ele desenvolveu destacada contribuição às atividades de ação cultural e extensão universitária, como Diretor do Instituto de Geografia, dando especial atenção aos professores e alunos do ensino fundamental e médio, particularmente da rede pública.

Personalidade culta, com forte base humanista e artística, o Professor Carlos Augusto abriu canais de inovação da geografia também a partir das artes, com especial destaque para a literatura, o teatro e as artes visuais. Foi por sua influência que um dos primeiros trabalhos por mim realizados, voltado para o ensino de climatologia e destinado aos professores do ensino fundamental e médio, apresentou-se com uma âncora literária, explorando texto de Graça Aranha em seu "Canaã".

Poderia me estender muito mais, todavia acho que já apresentei resumidamente alguns argumentos que me permitem identificar o Prof. Carlos Augusto de Figueiredo Monteiro como uma das principais referências acadêmicas do departamento de Geografia no período em que ele integrou seu quadro de docentes ativos. É evidente que sua liderança continuou presente nos anos que se seguiram, porém, infelizmente, seu papel junto aos alunos de graduação passou a ser menor, principalmente através de processos indiretos ou externos ao próprio Departamento. De qualquer forma, ainda hoje não se pode entender o Departamento de Geografia da USP sem a atuação do Prof. Carlos Augusto de Figueiredo Monteiro durante aquelas duas décadas finais do curto século XX. 
